\title{
Preliminary Findings into Thermal Properties of Specific Stratigraphy for Geothermal Energy Prospecting Along the Williston Basin
}

\author{
R. R. Koon Koon ${ }^{1, *}$, I. Haraksingh ${ }^{2}$, L. Ufondu ${ }^{3}$ \\ ${ }^{1}$ Department of Physics, University of the West Indies, Mona Campus, Jamaica \\ ${ }^{2}$ Department of Physics, University of the West Indies, St. Augustine Campus, Trinidad \\ ${ }^{3}$ Department of Civil \& Geological Engineering, University of Saskatchewan, Saskatoon, SK, Canada
}

Copyright $\bigcirc 2017$ by authors, all rights reserved. Authors agree that this article remains permanently open access under the terms of the Creative Commons Attribution License 4.0 International License

\begin{abstract}
The paper focuses on the thermal evaluation of geological well data along the Williston Basin, possessing the greatest potential for geothermal energy development. The research follows the criteria for possible electrical generation through binary type systems for medium-temperatures exceeding $80^{\circ} \mathrm{C}$. The bottom-hole temperatures (BHTs) obtained from the geological well data are corrected to thermal equilibrium through the Harrison correction method, from which the findings clearly point to the Estevan $103.5^{\prime} W$ region, as the best geothermal energy prospect for a binary type system. Three wells having the highest recorded temperatures at depth are seen in particular with well locators of 101/11-14-002-09W2/00, 121/10-28-001-10W2/02, and 141/03-08-001-11W2/00 having temperatures of $106^{\circ} \mathrm{C}, 100^{\circ} \mathrm{C}$ and $127^{\circ} \mathrm{C}$ at depths respectively. The thermal distribution map serves as a preliminary tool for investigating the potential of the Williston Basin for geothermal energy development. These maps, coupled with hydraulic maps, can be used as an enhanced method of determining prospective site locations for wells. Finally, temperatures above $80^{\circ} \mathrm{C}$ were found at depths exceeding $2250 \mathrm{~m}$ for the Williston Basin, overlying the Winnipeg and Deadwood formations.
\end{abstract}

Keywords Williston Basin, Thermal Equilibrium, Estevan, Thermal Distribution Maps

\section{Introduction}

Geothermal energy is a clean and renewable energy source which utilizes the thermal properties of the earth's crust to generate energy which can be used for the heating and cooling of buildings, and generation of electricity. The former has gained an extensive application in Canada. So far, Canada has not produced electrical energy from this source
[7]. The potential of geothermal energy resources is broadly distributed across the Provinces. The paper focuses on the regions of Estevan (divided into Estevan $103.5^{\prime} \boldsymbol{W}$ and Estevan $\mathbf{1 0 5}^{\prime} \boldsymbol{W}$ ), and Weyburn under the Province of Saskatchewan. Preliminary investigations into one hundred and thirty-eight abandoned oil wells were utilized for the research. The approach only serves to act as a template for much greater and intensive analysis of well core data of other regions within Saskatchewan.

\subsection{Sedimentary Basin}

For the purposes of this paper the Sedimentary Basin is of particular interest. Significant volumes of fluid in porous rocks are contained within the sedimentary basin. The Western Canada Sedimentary Basin (WCSB) is the largest and best characterized sedimentary basin in Canada. Its vast expanse begins from the foothills of Alberta, cutting through southern Saskatchewan. The WCSB possesses a maximum depth of approximately $5.4 \mathrm{~km}$ [9], [17]. It can be noted that the WCSB acts as a thermal 'blanket' owing to the fact that sedimentary rocks characteristically have low thermal conductivity values, as a result trapping heat and generating higher geothermal gradients [7]. There exists a substantial volume of porous rocks containing abundant amount of fluids within the sedimentary basin. These fluids are mainly comprised of water, and also accumulation of oil and gas.

The target area been investigated is highlighted within the green rectangle of Figure 1. This area falls within the Williston basin which is part of the WCSB. The Williston Basin is a cratonic basin within the WCSB in Saskatchewan, which extends to eastern Montana, South and North Dakota in the USA. It is covered by sedimentary rocks of Cambrian to Tertiary with thickness of over $4.9 \mathrm{~km}$ [10].

As outlined by Grasby [7] from the Open file 6914 report on Geological survey of Canada, British Columbia has the highest potential for immediate geothermal energy development as a result of the manifestation of physical 
indicators such as thermal springs. However, areas of the WCSB displaying known temperatures between $80^{\circ} \mathrm{C}-$ $150{ }^{\circ} \mathrm{C}$ are regions of potential binary systems. Therefore for a geothermal reservoir exhibiting medium-temperature above $80^{\circ} \mathrm{C}$, electricity can still be generated by means of a binary cycle plant [7]. Hence this benchmark value of $80^{\circ} \mathrm{C}$ is used throughout the investigation as a means to categorize different regions and the potential associated with each.

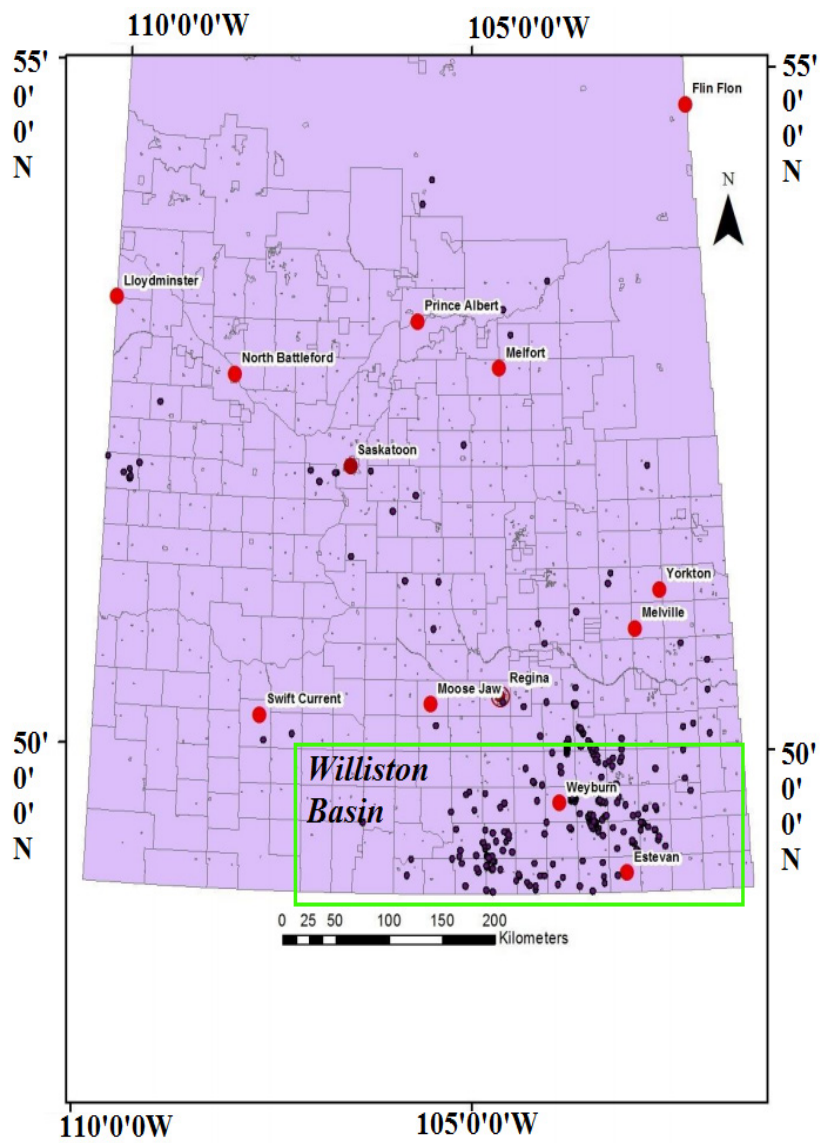

Figure 1. Distribution of well locations across the Province of Saskatchewan

Under the Executive Summary, Research Needs of the Geological Survey of Canada Open File 6914, it states, "New combined field, laboratory and computer modelling investigations are needed to fill data gaps. Most of Canada has no geothermal information, and in many regions where information exists, the data are insufficient to characterize geothermal resources" [7]. Hence the paper serves to satisfy this concern by presenting initial findings based on simulated results of existing data from which a more vivid understanding of the formations are attained.

\section{Major Geological Formations within Saskatchewan}

The wells used for this study are located within the Williston Basin across the areas of Estevan and Weyburn as shown in Figure 1. These wells cut across the sedimentary deposits of Deadwood, Red River, Winnipeg, and Yeoman Formations within the Williston Basin of the Western Canada Sedimentary Basin. The Winnipeg formation was deposited during the Middle Ordovician period; it is conformably overlain by the carbonates of the Upper Ordovician Red River formation and lies unconformably over lower Ordovician sediments [12], [16]. The formation is composed of mainly clastic rocks, which consists predominantly of sandstone, and also siltstone and shale deposited by transgression since the middle Ordovician period [4], [11]. The Winnipeg formation according to Paterson [12] is divided into two member units; the lower unit which comprises quartz-rich sandstone with minor siltstone and shale called Black Island member and the upper unit comprising green waxy shale with small quantity of siltstone and shaly quartz-rich sandstone [12].

The Red River formation is composed of dolomite and limestone deposited during the Upper Ordovician period. It is sub-divided into four member units from top to bottom; Fort Garry member (crystalline dolomite), Selkirk Member (fossil-rich dolomitic limestone), Cat Head member (silica-rich dolomite) and Dog Head member (fossil-rich dolomitic limestone)-[2]. The Yeoman formation sometimes referred to as lower Red River formation [11] is overlain by Herald formation (which correlates to the Fort Garry member of the Red River Formation) and it is found in the southeastern Saskatchewan where it is underlain by the Winnipeg Formation. It is mainly composed of carbonate rocks (limestone and dolomite). The flow of brine within these deep sedimentary formations is predominantly horizontal with little or no vertical flow due to the low permeability confining shale units [3].

The Winnipeg formation consists of sandstone structure with unconformities lining this region. While the Deadwood formation is an alternating consistence of sandstone and shale structure with also unconformities at its initial and final lining of the formation. The dominant fluid flow path within these formations is horizontal.

\section{Temperature Findings for the Regions of Weyburn and Estevan}

\subsection{Bottom-Hole Temperatures (BHTs) versus True Vertical Depths (TVDs) Graphical Representation for each Region}

The bottom-hole temperatures (BHTs) obtained from the geological well data has to be corrected to thermal equilibrium. These corrections can be seen for each of Figures 2 and 3 as the Linear Harrison Correction Method $(\mathrm{HCM})$ or Thermal Equilibrium plots. BHT data are usually of low quality as mentioned by Blackwell et al. $(2007 ; 2010)$ and Shope et al. (2012). The true formation temperature values are not represented by the geophysical logs. This is 
as a result of recording the data shortly after cessation of drilling operation. These corrections can be seen for each of
Figures 2 and 3 as the Linear Harrison Correction Method (HCM) or Thermal Equilibrium plots.
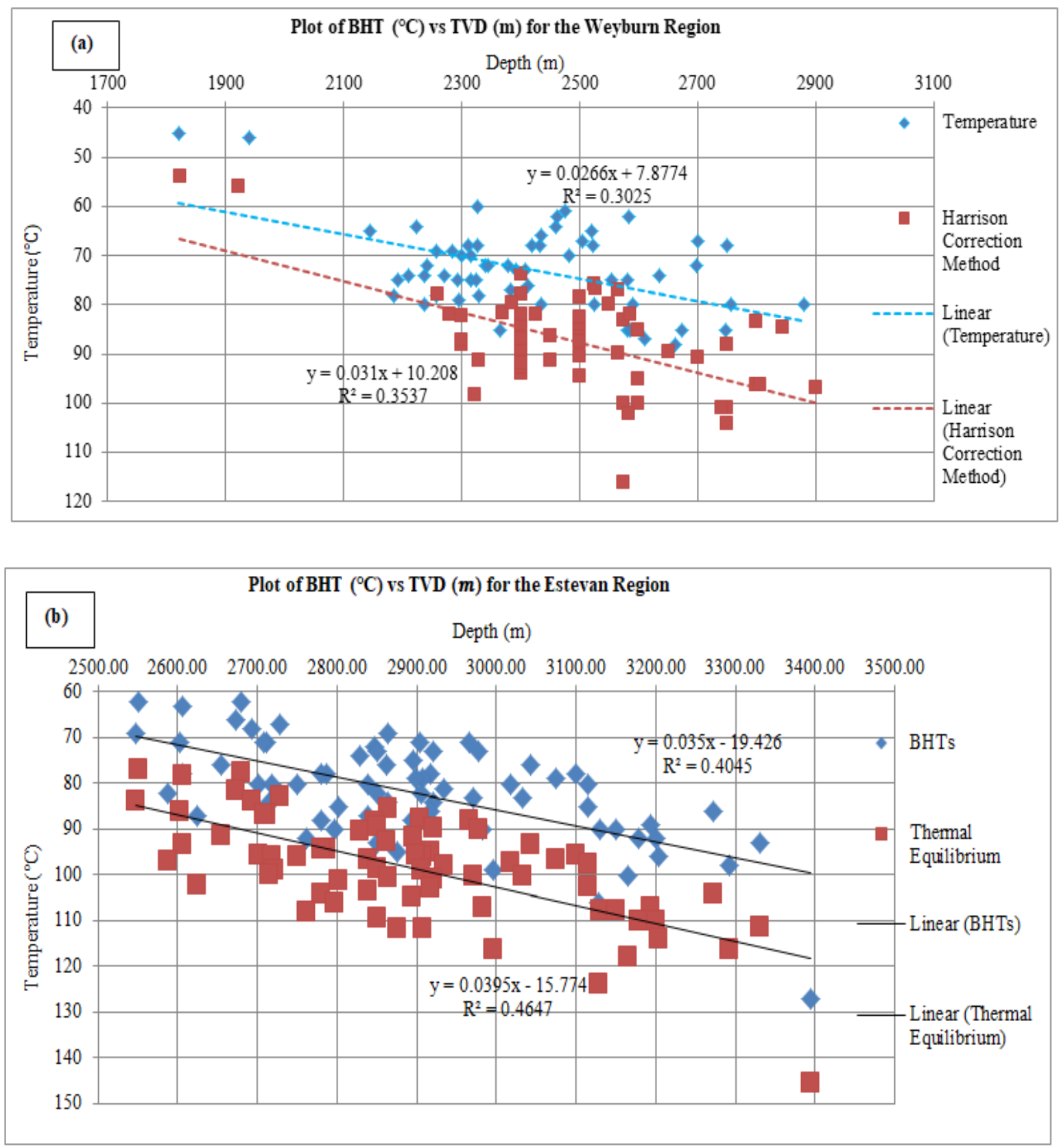

Figure 2. Graphical representation of temperature findings at depth for (a) Weyburn (66 wells), (b) Estevan (72 wells) regions across the Williston Basin 


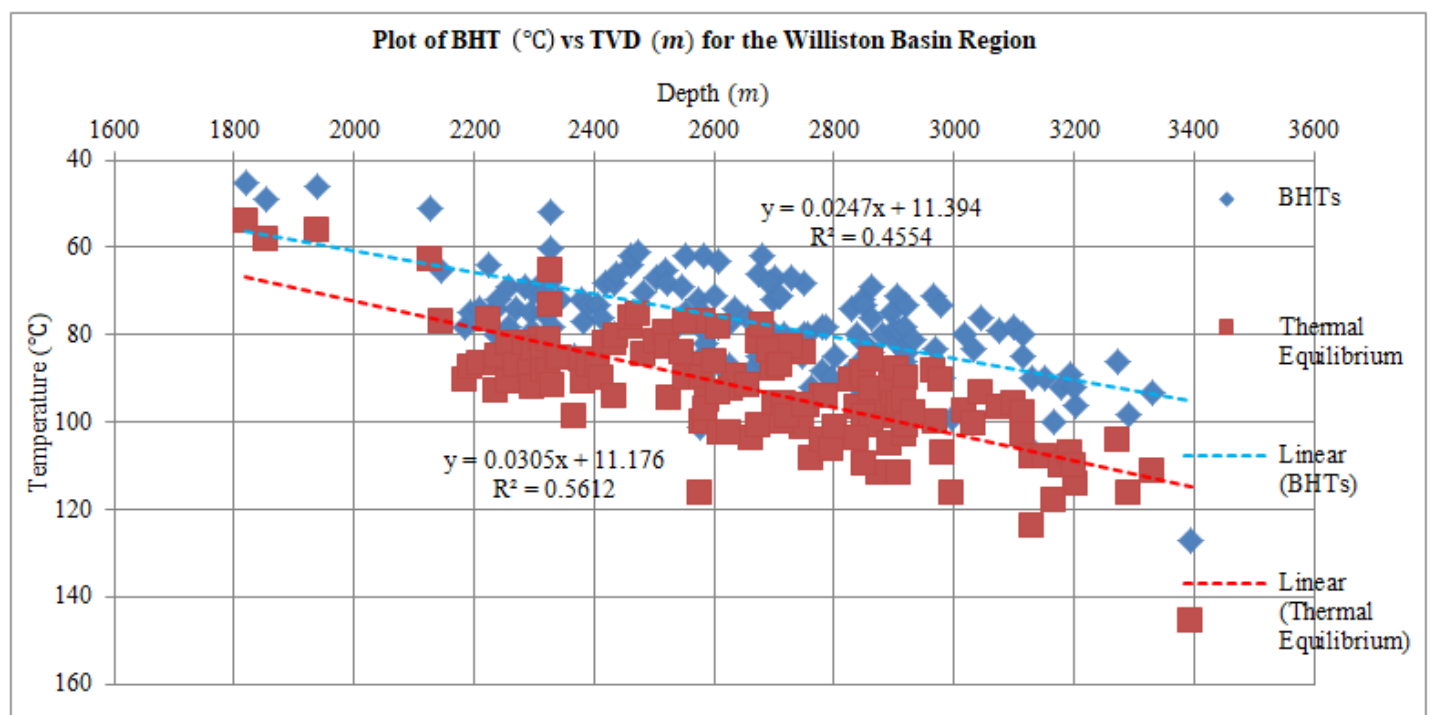

Figure 3. Graphical representation of temperature findings at depth for all 138 wells investigated across the Williston Basin

Table 1. Temperature distribution across the investigated regions and the Williston Basin for thermal equilibrium wells

\begin{tabular}{|c|c|c|c|c|}
\hline Depth $(\mathrm{m})$ & Weybum $\left({ }^{\circ} \mathrm{C}\right)$ & Estevan $105^{\prime} W\left({ }^{\circ} \mathrm{C}\right)$ & $\begin{array}{c}\text { Estevan } 103.5^{\prime} W \\
\left({ }^{\circ} \mathrm{C}\right)\end{array}$ & Williston Basin $\left({ }^{\circ} \mathrm{C}\right)$ \\
\hline 500 & 25.708 & 13.6214 & -17.641 & 26.426 \\
\hline 750 & 33.458 & 22.1214 & -4.866 & 34.051 \\
\hline 1000 & 41.208 & 30.6214 & 7.909 & 41.676 \\
\hline 1250 & 48.958 & 39.1214 & 20.684 & 49.301 \\
\hline 1500 & 56.708 & 47.6214 & 33.459 & 56.926 \\
\hline 1750 & 64.458 & 56.1214 & 46.234 & 64.551 \\
\hline 2000 & 72.208 & 64.6214 & 59.009 & 72.176 \\
\hline 2250 & 79.958 & 73.1214 & 71.784 & 79.801 \\
\hline 2500 & 87.708 & 81.6214 & 84.559 & 87.426 \\
\hline 2750 & 95.458 & 90.1214 & 97.334 & 95.051 \\
\hline 3000 & 103.208 & 98.6214 & 110.109 & 102.676 \\
\hline
\end{tabular}

The IHS AccuMap and Geoscout provided the required well core data for the Province of Saskatchewan. The HCM is made possible typically through data constraints with publicly available oil and gas well information. An empirical correction factor is used, as demonstrated by Harrison [8], Blackwell [1], Frone and Blackwwell [5], and Shope [14]. The Harrison correction can be described as a second order polynomial function of depth. Through this method the generated temperature correction factor, $\Delta T$, value in ${ }^{\circ} \mathrm{C}$ is a correction factor that is summed to the BHT from the geological well data to yield an estimated equilibrium temperature. It is stated by the following:

$$
\Delta^{\circ} \mathrm{C}=-16.51+0.01827 z-2.345 \times 10^{-6} z^{2}
$$

It is observed from Figures 2 and 3, other than the rectification of the well data to thermal equilibrium, it also increases the $R^{2}$ value (accounts for a greater correlation between the temperature and depth values). All one hundred and thirty-eight wells within the Williston Basin are used to generate the resulting plots on Figure 3 . The thermal equilibrium trend line yields a useful equation of temperature as a function of depth $(y=0.0305 x+$ 11.176) within the Williston Basin. From initial observations of the well data for Estevan, it exhibited a wide variation of temperature values across this region; therefore, the well data was divided into Estevan $105^{\prime} W$ and Estevan $103.5^{\prime} W$ subsections. The wells centralized to these subsections were grouped and categorized accordingly. Each section generated a linear thermal equilibrium equation. Hence all resulting equations of these LTE trend lines are used in calculation of the temperatures at depth as seen in Table 1. As stated earlier from literature, electrical generation is possible at medium-temperatures greater than $80^{\circ} \mathrm{C}$ via a binary cycle plant. Therefore, as seen in Table 1, the blue-dashed box highlights this benchmark value of greater than $80^{\circ} \mathrm{C}$ values; this is attained at a minimum depth of $2500 \mathrm{~m}$. Furthermore, Figure 4 emphasizes this finding as seen by the red-dashed line that cuts through all plots prior to the $2500 \mathrm{~m}$ depth mark. 


\subsection{Identification of Probable Location of a Binary Type Plant}

The LTE trend line for the Williston Basin plot as seen in Figure 4 , illustrates temperatures above $80^{\circ} \mathrm{C}$ for depths exceeding $2256.5 \mathrm{~m}$. This cratonic basin within the WCSB in Saskatchewan extends to Eastern Montana, South and North Dakota in the USA. Furthermore, at depths of $2500 \mathrm{~m}$ and more, the Winnipeg and Deadwood formations can be found. Most of these Estevan $103.5^{\prime} \mathrm{W}$ wells are located within the $49^{\circ} 0^{\prime} 0^{\prime \prime} N-49^{\circ} 4^{\prime} 0^{\prime \prime} N$ latitude. However, there are three wells in particular at depths of $3128.0 \mathrm{~m}, 3165.0 \mathrm{~m}$ and $3394.9 \mathrm{~m}$, and at temperatures of $106^{\circ} \mathrm{C}, 100{ }^{\circ} \mathrm{C}$ and $127^{\circ} \mathrm{C}$ respectively all of the Yeoman formation. Underlying this formation are the Winnipeg and Deadwood formations. These bottom-hole temperatures based on their latitude and longitude coordinates have been localized around the dashed-red oval in Figure 5, ideally being located centrally on the Williston Basin.

Weyburn has the second highest temperature gradient, registering a temperature of $95.05^{\circ} \mathrm{C}$ at a depth of just $2750 \mathrm{~m}$. Weyburn lies within the boundary of the Williston Basin; hence wells south and south-west will begin to exhibit higher temperature values. Estevan $105^{\prime} W$ also lies within the range of the basin recording a temperature of $90.12{ }^{\circ} \mathrm{C}$ at a similar $2750 \mathrm{~m}$ mark.

\subsection{Surfer 13 Distribution Maps}

Firstly, the well identification numbers, BHTs, latitudes and longitudes of all 138 wells investigated are tabulated into an Excel file. Secondly the Harrison correction factor is determined for each BHT value. Once the data is correctly formatted within the Excel file, it is then loaded into the Surfer 13 software. A 2D contour thermal distribution map is generated, from which a 2D Post map of all the well locations investigated is overlaid onto the first. Through proper alignment of the grid Figure 6 is successfully obtained. The temperature distribution map as seen in Figure 6 clearly summarizes the findings of the BHT values across the southern portion of the Province. The immediate focus is captured south-southeast of Saskatchewan within the Williston basin on the Canada-United States border line. Within the $103.5^{\circ} \mathrm{W}-102.5^{\circ} \mathrm{W}$ longitude mark and south of the $49.5^{\circ} \mathrm{N}$ latitude mark indicates areas for the highest probable potential for geothermal hot spots.

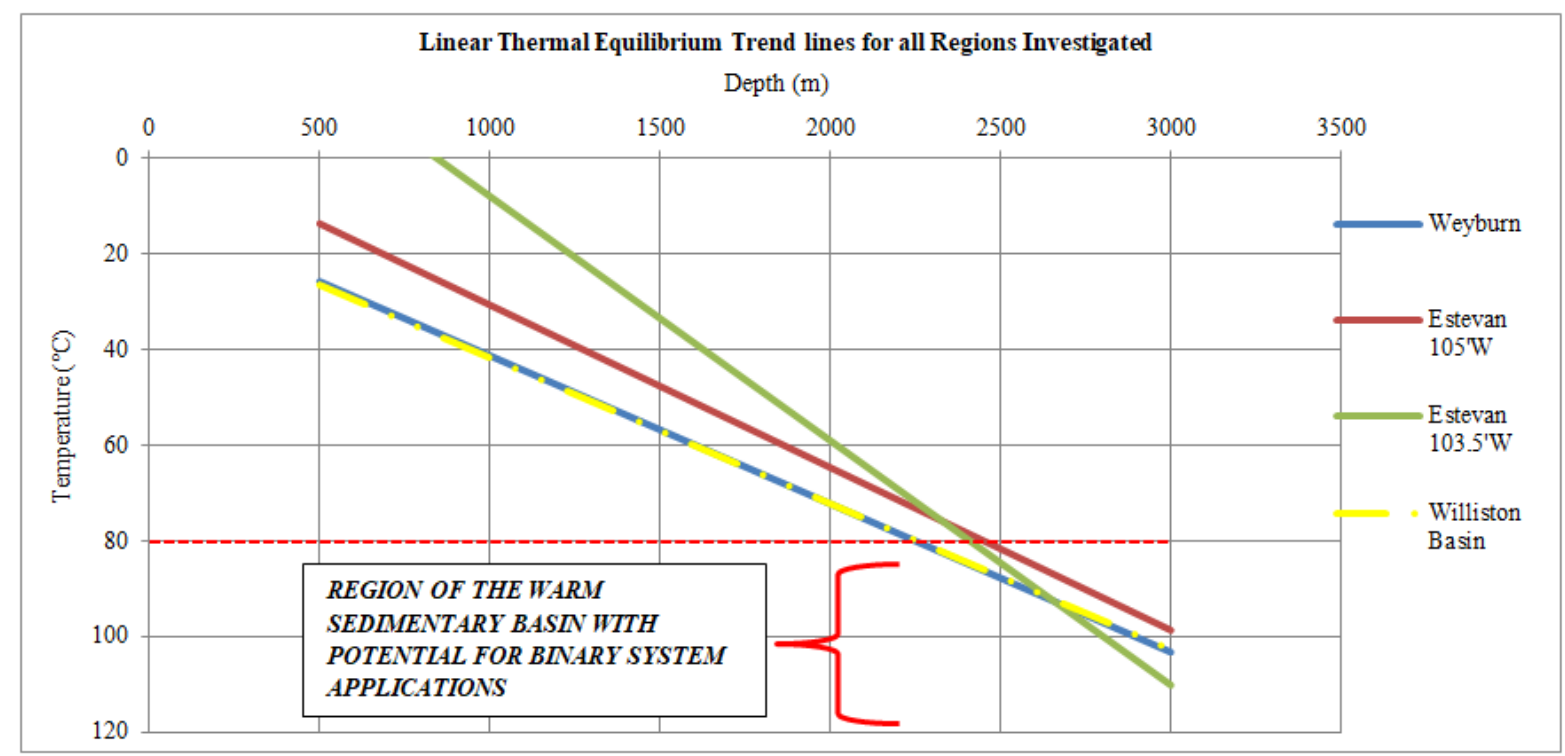

Figure 4. Graphical representation of thermal equilibrium findings at depth for all regions investigated and a minimum limiting value of $80{ }^{\circ} \mathrm{C}$ highlighted for binary system applications across the Williston Basin 


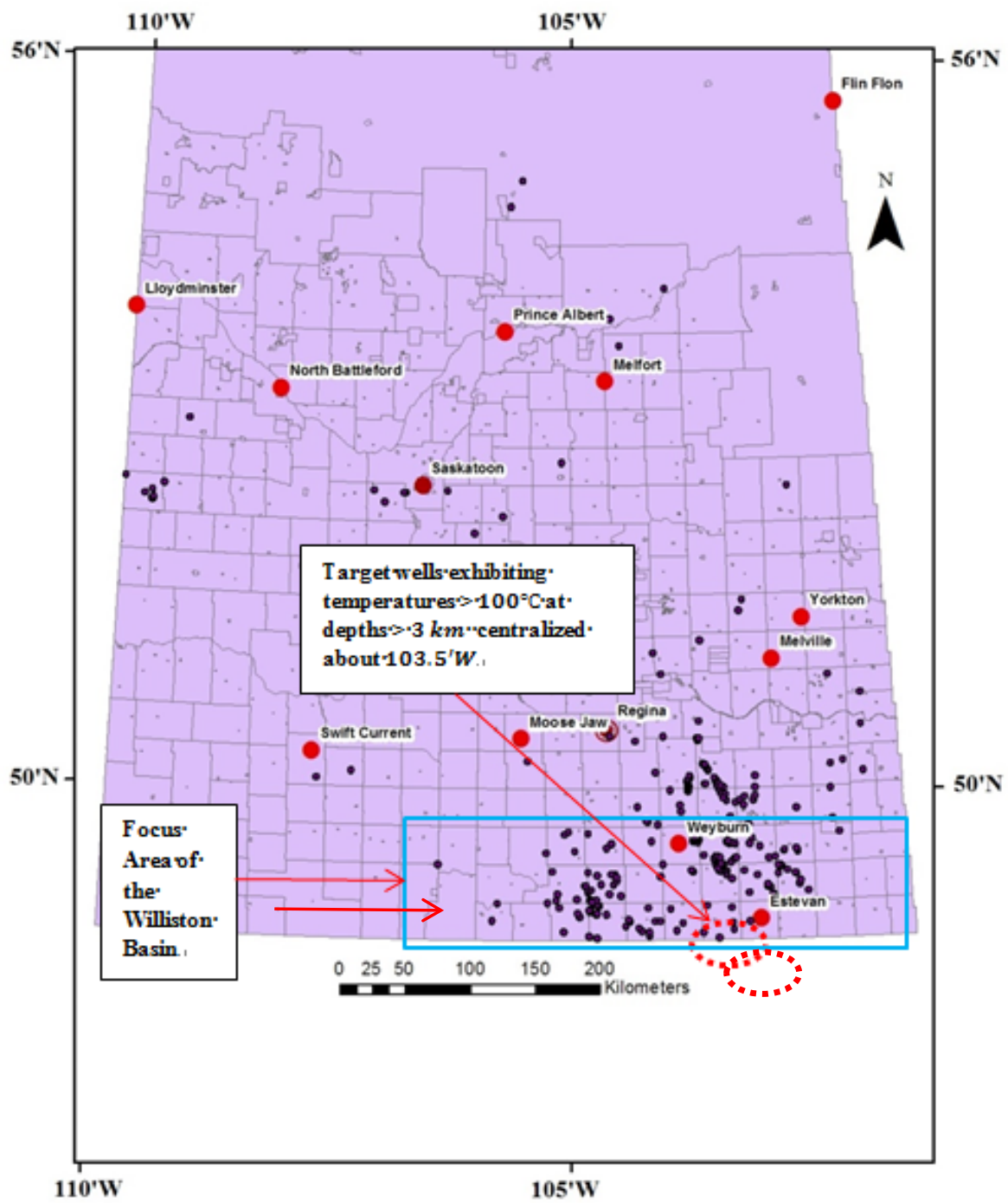

Figure 5. Location of target wells exhibiting temperatures greater than $100^{\circ} \mathrm{C}$ at depths greater than $3 \mathrm{~km}$ for probable binary type system applications

Temperature Distribution and Post Map Along the Williston Basin at Depths Greater Than $2.5 \mathrm{~km}$ Within th Province of Saskatchewan

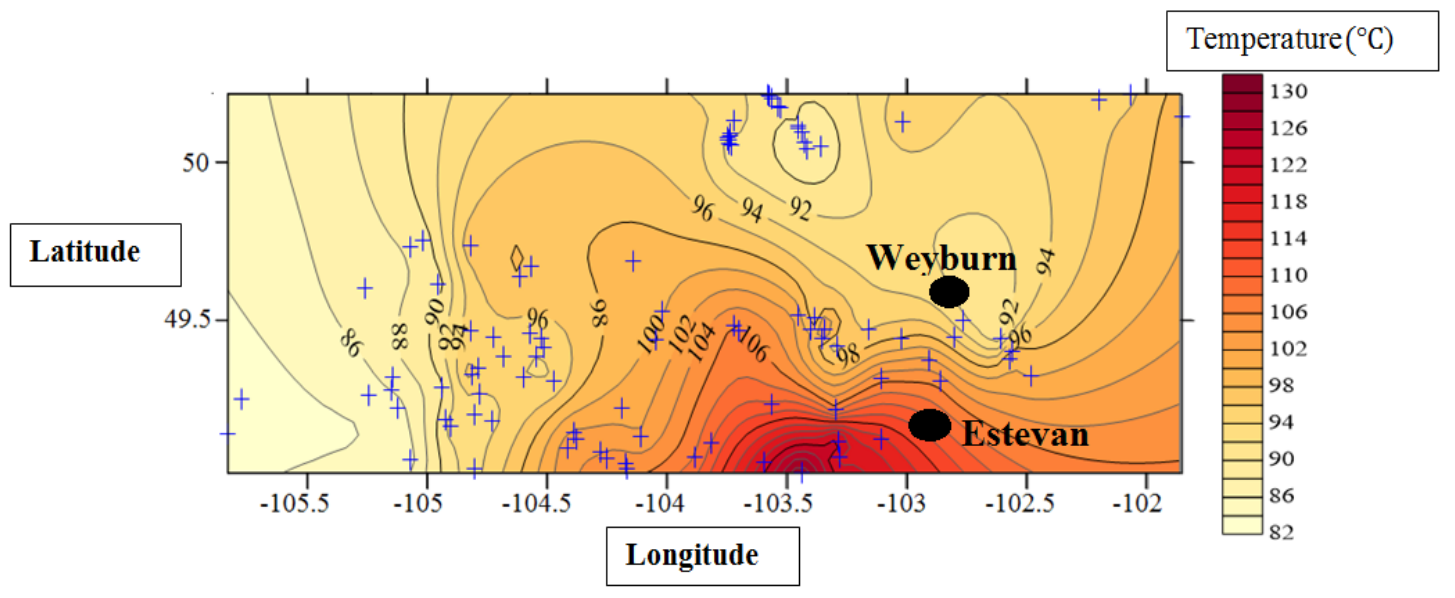

Figure 6. Temperature distribution and Post map of all 138 wells south of the Province of Saskatchewan 


\section{Discussion}

The two primary areas of Estevan and Weyburn were selected because of significantly enhanced temperatures at depth. Linear Thermal Equilibrium trend lines of $y=0.0395 x$ - 15.774 and $y=0.031 x+10.208$ for Estevan and Weyburn respectively were determined. Both LTE trend lines for Estevan $103.5^{\prime} \mathrm{W}$ and Weyburn converge at $95.05^{\circ} \mathrm{C}$ at the $2750 \mathrm{~m}$ mark. The LTE trend line for Weyburn reaches the $80^{\circ} \mathrm{C}$ boundary before that of Estevan $103.5^{\prime} \mathrm{W}$. However, the LTE trend line for Weyburn soon lags behind Estevan $103.5^{\prime} \mathrm{W}$ for all depths exceeding the $2750 \mathrm{~m}$ mark, as seen in Table 1 and Figure 4.

From Figure 5, the ArcGIS map highlights three Estevan $103.5^{\prime} W$ wells which are within the approximate coordinate ranges for the Williston Basin from $\left(49^{\circ}-50^{\circ}\right) N$ to $\left(102^{\circ}-104^{\circ}\right) \mathrm{W}$. Generally it is observed that the BHTs increase the closer the well is located to the $49^{\circ} \mathrm{N}$ latitude, (the international border line separating Canada from the United States of America), and localized to the $103^{\circ} \mathrm{W}$ longitude mark. The well I.D. of these three wells of interest highlighted in Figure 5 are, 101/11-14-002-09W2/00, 121/10-28-001-10W2/00, and 141/03-08-001-11W2/00, having BHTs of $106^{\circ} \mathrm{C}, 100^{\circ} \mathrm{C}$ and $127^{\circ} \mathrm{C}$ respectively.

These all exhibit increasing temperature with decreasing latitude, and localized to the $103^{\circ} \mathrm{W}$ longitude mark tending towards the region of the Williston Basin having greater depth of the Sedimentary Basin. These three wells having BHTs of $106^{\circ} \mathrm{C}, 100{ }^{\circ} \mathrm{C}$ and $127^{\circ} \mathrm{C}$, are at depths of $3128.8 \mathrm{~m}, 3165.0 \mathrm{~m}$, and $3394.9 \mathrm{~m}$, for the Winnipeg, Yeoman, and Deadwood formations respectively. In addition, the majority of formations at depth for the BHTs attained from the AccuMap and Geoscout data were among the Winnipeg, Deadwood, and Pre-Cambrian. Hence the thermal distribution map, serves to pinpoint specific locations along the Williston basin of high thermal values for geothermal energy prospecting.

\section{Conclusions}

Through the application of well core data from across the Province of Saskatchewan, the areas of Weyburn and Estevan within the Williston Basin were investigated thoroughly with regards to the thermal properties of these areas of interest. The extent of these thermal findings was clearly represented through BHT vs TVD plots and the Harrison correction factors were taken into account for the rectification of the well data to thermal equilibrium.

The findings strongly point towards three Estevan $103.5^{\prime} W$ wells within the approximate coordinate ranges for the Williston Basin from $\left(49^{\circ}-50^{\circ}\right) N$ to $\left(102^{\circ}-104^{\circ}\right) \mathrm{W}$. The well I.D. of these three wells of interest highlighted in Figure 5 are: 101/11-14-002-09W2/00, 121/10-28-001-10W2/00, and 141/03-08-001-11W2/00, having BHTs of $106^{\circ} \mathrm{C}, 100{ }^{\circ} \mathrm{C}$ and $127^{\circ} \mathrm{C}$ respectively. Therefore, these target wells are the best probable locations for further investigations of geothermal energy prospecting.

The thermal distribution map serves as a preliminary tool for investigating the potential of the Williston Basin for geothermal energy development. These maps, coupled with hydraulic maps, can be used as an enhanced method of determining prospective site locations for wells. Finally, temperatures above $80^{\circ} \mathrm{C}$ were found at depths exceeding $2250 \mathrm{~m}$ for the Williston Basin, overlying the Winnipeg and Deadwood formations.

\section{Acknowledgements}

Special mention must be given to the academic staff members at the University of Saskatchewan, Department of Civil \& Geological Engineering, Saskatchewan, Canada. Through research collaborations with Prof. Ferguson and discussions with Prof. Hawkes, ideas on data applications were attained. In addition, the assistance of Mr. Ufondu, was important in accessing geological well core logs from IHS AccuMap (AccuLogs). The geological logs are accessed via https://www.ihs.com/products/oil-gas-tools-accumap.html.

\section{REFERENCES}

[1] Blackwell, D. D., Negraru, P. T., and Richards, M. C. (2007), "Assessment of the Enhanced Geothermal System Resource Base of the United States," Natural Resource Research, 15, December 2006, 283-308.

[2] Blackwell, D. D., Batir, J., Frone, Z., Park, J., and Richards, M. (2010). "New geothermal resource map of the northeastern US and technique for mapping temperature at depth." GRC Transactions, Volume 34. Document ID 28663.

[3] Carroll, W. K., 1979, Depositional environments and paragenetic porosity controls, upper Red River Formation, North Dakota: North Dakota Geological Survey Report of Investigation $66,51 \mathrm{p}$.

[4] Ferguson G, Betcher RN, Grasby SE (2007) Hydrogeology of the Winnipeg Formation in Manitoba, Canada. Hydrogeology J 15(3):573-587. doi:10.1007/s10040-006-0130-4

[5] Ferguson G, Grasby SE (2014). The geothermal potential of the basal clastics of Saskatchewan, Canada. Hydrogeology J 22(1):143-150

[6] Frone, Z., and Blackwell, D. D. (2010), "Geothermal Map of the Northeast United States and the West Virginia Thermal anomaly," GRC Transactions, Volume 34, 2010.

[7] Gionvannozzi, R. 1990. "Contruzione di Macchine." Volume II, Patron-Bologna.

[8] Grasby, S. E., D. M. Allen, S. Bell, Z. Chen, G. Ferguson, A. Jessop, M. Kelman, M. Ko, J. Majorowicz, M. Moore, J. Raymond, and R. Therrien. 2012. Geothermal Energy Resource Potential of Canada. Geological survey of Canada open file 6914.

[9] Harrison, W. E., Luza, K. V., Prater, M. L., and Chueng, P. K. 
(1983), "Geothermal resource assessment of Oklahoma:, Special Publication 83-1, Oklahoma Geological Survey, 1983.

[10] Hitchon, B. 1984. Geothermal gradients, hydrodynamics, and hydrocarbons occurrences, Alberta, Canada. Bulletin, American Association Petroleum Geology, 68, 713-743

[11] Kent DM and Christopher JE (1991): Geological History of the Williston Basin \& Sweetgrass Arch; in O'Connell, S.C. (1994): Geological history of the Peace River Arch; in Geological Atlas of the Western Canada Sedimentary Basin, G.D. Mossop and I. Shetsen (comp.), Canadian Society of Petroleum Geologists and Alberta Research Council, URL http://www.ags.gov.ab.ca/publications/wcsb_atlas/atlas.html

[12] Norford BS, Haidl FM, Besyz RK, et al (1994) Middle Ordovician to Lower Devonian strata of the Western Canada Sedimentary Basin. In: Geological atlas of the Western Canada Sedimentary Basin. Canadian Society of Petroleum Geologists/Alberta Research Council, Calgary, AB, pp 109127

[13] Paterson DF (1971) The stratigraphy of the Winnipeg Formation (Ordovician) of Saskatchewan. Saskatchewan Dept. of Mineral Resources Geological Report 140, Gov. of
Saskatchewan, Regina, SK, 57 pp

[14] Popov, E. P. 1990. Engineering Mechanics of Solids. Prentice-Hall Inc. University of California, Berkley.

[15] Shope, E. N. et al. (2012), "Geothermal Resource Assessment: A Detailed Approach to Low-Grade Resources in the State of New York and Pennsylvania," $37^{\text {th }}$ Stanford Geothermal Workshop, Stanford, CA, January 30-February 1, 2012. (In Press)

[16] Silvano, S. 2010. "Mathematical model of the Lamé Problem for Simplified Elastic Theory applied to Controlled-Clearance Pressure Balances." Online available from http://arxiv.org/abs/1007.0813

[17] Slind OL, Andrews GD, Murray DL et al (1994) Middle Cambrian to Lower Ordovician strata of the Western Canada Sedimentary Basin. In: Mossop GD, Shetsen I (eds) Geological atlas of the Western Canada Sedimentary Basin. Canadian Society of Petroleum Geologists/Alberta Research Council, Calgary, AB, pp 87-108

[18] Sproule and Angus Ltd. 1981. Report on preliminary assessment of the potential applications of geothermal energy. Earth Physics Branch, EMR. Open File 81-7, 86p 